ISSN: 0212-0267

DOI: http: //dx.doi.org/ro.I420I/hedu201938195222

\title{
EL USO DE LAS LENGUAS \\ EN LOS SISTEMAS DE ENSENAANZA DE LA EUROPA RENACENTISTA
}

\section{The use of the languages in the educational systems of the Europe Renaissance}

\author{
Juan Luis Monreal Pérez \\ Investigador del Grupo de Investigación "La Filosofía y los procesos sociobistóricos \\ contemporáneos» (EogI-oI). Universidad de Murcia \\ Correo-e: jlmonreal@um.es
}

Recepción: I2 de julio de 20I8. Envío a informantes: 6 de septiembre de 2018

Aceptación definitiva: I8 de marzo de 2019

Resumen: Una de las aportaciones que hicieron los llamados humanistas renacentistas a la educación fue la organización de sus contenidos a través de los llamados sistemas de enseñanza o Ratio studiorum, desarrollando -a su vez- estrategias e instrumentos de aprendizaje. Uno de dichos instrumentos fue la lengua, en su vertiente comunicativa y de acceso al conocimiento. Entre dichos humanistas conviene mencionar a Erasmo, Vives, Ignacio de Loyola, Melanchthon y Calvino, por sus contribuciones al desarrollo de la lengua y, especialmente, por el peso que le dieron a la presencia de las lenguas en los sistemas de enseñanza que propusieron.

Palabras Clave: humanistas renacentistas; Ratio studiorum; lenguas y sistemas de enseñanza.

Aвstract: One of the contributions that the so called Renaissance humanists did to the education was the organization of its contents through the educational systems or Ratio studiorum; while developing at the same time strategies and instruments of learning, such as the language, considered in its communicative dimension and as a mean to access knowledge. Among the above mentioned humanists, Erasmus, Vives, Ignacio de Loyola, Melanchthon and Calvino may be stressed for their contributions to the development of the language and, specially, for the importance they provided to the languages in the educational systems they proposed. 
KEY WORDS: renaissance humanists; Ratio studiorum; languages and educational systems.

\section{Introducción}

$\mathrm{U}$

na de las contribuciones significativas del Renacimiento europeo a la educación fue la organización de los contenidos del aprendizaje a través de los llamados sistemas de enseñanza o Ratio studiorum. No cabe duda de que el esfuerzo de sistematización que se llevó a cabo en aquella época permitió repensar la educación y con ello organizar los contenidos de la enseñanza y desarrollar estrategias e instrumentos de aprendizaje. Uno de dichos instrumentos fue la lengua, en su vertiente comunicativa y de acceso al conocimiento.

Desde esta perspectiva, el presente artículo busca dos objetivos. El primero de ellos es identificar y analizar a humanistas renacentistas europeos que hicieron una contribución significativa al sistema de enseñanza y a la organización de los contenidos del mismo, tales como Erasmo, Vives, Ignacio de Loyola, Melanchthon y Calvino. Y el segundo objetivo del texto es examinar, por una parte, la presencia de las lenguas en los sistemas de enseñanza que estos humanistas nos han legado; y, por otra, analizar la función que cada uno de ellos asigna a la lengua, tanto como instrumento de aprendizaje cuanto como vehículo comunicativo.

\section{Sistemas de enseñanza y planes de estudio en la Europa renacentista}

La finalidad de todo sistema de enseñanza es lograr el aprendizaje que se define como necesario para formar a los ciudadanos en el bien de la educación. Dicho aprendizaje incluye los diferentes elementos que se consideran imprescindibles para la formación de las personas y para la adquisición de competencias sociales y profesionales.

El logro del aprendizaje por parte del sistema de enseñanza exige que los diferentes contenidos estén ordenados y organizados de forma sistémica; lo que significa que hay que definir bien el qué, el cuánto, el cómo, el cuándo y el dónde de los contenidos de cada uno de los elementos objeto de aprendizaje (Eisner, I983: 257).

Los sistemas de enseñanza ocupan, por tanto, un lugar central en las políticas educativas, y forman parte de las preocupaciones de todos los actores que intervienen en los sistemas educativos, se trate de políticos, de profesores, de alumnos y, por supuesto, de la ciudadanía en general. Pero dicha centralidad no solo existe hoy, sino que viene ocupando un espacio relevante desde hace ya varios siglos. Concretamente, desde la Europa renacentista la cuestión de la enseñanza y su organización no ha dejado de ser una cuestión principal que ha formado parte del pensamiento humanístico europeo. Baste recordar, al respecto, a Erasmo con su Plan de enseñanza de los discípulos, a Vives con sus Intuiciones psicológicas y 
renovadoras en relación a la enseñanza, a Ignacio de Loyola con su Ratio studiorum, a Melanchthon con su Organización escolar y a Calvino con las Leyes de la Academia de Ginebra (Labrador, I999a: 25). Cada uno de estos humanistas, desde posiciones religiosas diferentes, reformadoras u ortodoxas, asignaron a la enseñanza un papel fundamental, tanto desde la vertiente individual como societal. Todos entendieron que la enseñanza no produce los efectos deseados y necesarios si los contenidos que transmite no se organizan y adaptan a la realidad a través de un sistema bien articulado de cada uno de los elementos que lo integran. El resultado de dicha organización es el sistema de enseñanza que va a facilitar el aprendizaje de los contenidos educativos. A ninguno de estos humanistas les pasó desapercibido la importancia que tienen en el aprendizaje los aspectos didácticos, psicológicos, culturales e, incluso, sociológicos, hecho que le da modernidad a muchos de los planteamientos que hicieron varios siglos atrás.

Desde esta perspectiva, examinamos -a continuación- la contribución de cada uno de estos humanistas renacentistas, para analizar en detalle tanto su aportación a la construcción del sistema de enseñanza de su tiempo como la relevancia de las lenguas como instrumento de aprendizaje educativor.

\section{Erasmo y Juan Luis Vives, dos precursores de las Ratio studiorum ${ }^{2}$}

Las contribuciones de Erasmo y Vives al campo de la educación y de la enseñanza han sido significativas. Estas, en buena medida, están presentes en buena parte de sus escritos, poniéndose de manifiesto el interés que ambos tienen por la educación y la enseñanza, y que les lleva a reflexionar recurrentemente sobre ambas temáticas.

Hay algo común en ellos en relación a la enseñanza que conviene resaltar. En primer lugar, que su reflexión acerca de esta temática se hace de forma general, no sistematizada, y responde más bien a una parte de su filosofía humanística (Pardo, I889: 8) $)^{3}$ que a un plan de enseñanza organizado y sistematizado. En segundo lugar, que la referencia a la lengua constituye en ambos humanistas un elemento principal de su reflexión sobre la educación y la enseñanza, tanto desde la perspectiva del aprendizaje del saber, como de la comunicación humana y social. Teniendo en cuenta la forma no sistematizada de las contribuciones de Erasmo y Vives a la enseñanza, se puede hablar de ellos como dos precursores de las Ratio

La elección de los humanistas seleccionados para su análisis obedece a la aportación de los mismos al contenido del artículo, sistemas de enseñanza y planes de estudio en la Europa renacentista. La dimensión de un artículo explica los criterios restrictivos aplicados en la selección de autores; dicha decisión impide analizar a algunos otros humanistas considerados también como relevantes del periodo analizado.

2 Con carácter general se va a utilizar el término Ratio studiorum como equivalente a organización de los estudios y a plan de estudios.

3 Este texto, en forma de Conferencia, fue leído por su autora, en el Museo Pedagógico de Instrucción Primaria, el 30 de marzo de I889, y es parte, en cuanto libro, de la colección en poder de las librerías Bodleian de la Universidad de Oxford. 
studiorum que más tarde se elaboraron por parte de Ignacio de Loyola, Melanchthon y Calvino, en los que hay una propuesta organizada y sistemática de los contenidos de la enseñanza para sus correspondientes organizaciones escolares.

\section{I. Erasmo y la enseñanza de la lengua}

El análisis que Erasmo hace del sistema de enseñanza es una consecuencia de lo que entiende por ethos pedagógico, que «viene representado por las relaciones entre pensamiento, lenguaje y enseñanza» (Vergara, 2016: 256). La concreción de dichas relaciones es necesario realizarla y, a tal fin, el concepto y estructura de sistema de enseñanza es un instrumento adecuado para articularlas convenientemente, mediante la utilización de materiales de los que no se disponía. Para llenar dicho vacío, Erasmo no duda en acometer la producción de manuales filológicos y textos de educación ${ }^{4}$ que examinamos a continuación, con el fin de transmitir su pensamiento sobre la enseñanza en general y, en particular, sobre la enseñanza de las lenguas.

Conviene tener presente que el interés de Erasmo al analizar el sistema de enseñanza se centra, fundamentalmente, en las formas y edades del aprendizaje y en la función que la lengua desempeña, tanto en dicho proceso de aprendizaje como en ser un instrumento básico para la comunicación humana.

\subsection{Enseñanza y aprendizaje de la lengua}

Aunque Erasmo era consciente de que el proceso de aprendizaje dura toda la vida, desde que se nace hasta que se muere, sin embargo en sus escritos defiende y recomienda la necesidad de iniciar a los niños desde el mismo nacimiento en las buenas letras, por la sencilla razón de que cuando se es niño se tienen unas capacidades y habilidades especiales como la memoria, que es necesario rentabilizar y que producen unos efectos muy positivos en varias direcciones, como es el caso del aprendizaje de las lenguas. Concretamente, el texto de su obra De cómo los niños han de ser precozmente iniciados en la piedad y en las buenas letras (De pueris statim ac liberaliter instituendis, I529) $)^{5}$ lo dedica a reflexionar sobre esta cuestión de tanto alcance para el proceso general del aprendizaje. En dicho proceso de aprendizaje, Erasmo descubre que la cuestión didáctica juega un papel capital, ya que esta busca los mejores caminos a seguir para obtener la mejor enseñanza posible (Pardo, I889: I3-I4).

4 Javier Vergara presenta, en su capítulo del libro arriba mencionado (Vergara, 2016: 256-267), un resumen de las obras pedagógicas de Erasmo y que complementan la parte del texto del artículo dedicado a Erasmo.

La versión española utilizada de esta obra es la publicada por Lorenzo Riber en sus Obras escogidas de Erasmo (Madrid, Aguilar, 1964, pp. 917-962). Al respecto, se han tenido también en cuenta las notas de traducción que se hacen a esta versión de la obra de Riber por Joaquín Parellada en la obra Erasmo de Rotterdam (Madrid, Gredos, 20II, pp. 322-386). 
Coherente con este planteamiento didáctico, Erasmo aborda el aprendizaje de la lengua, cuestión que se constituirá en un elemento central de su concepción de la enseñanza, tal como lo recuerda en su escrito Plan de Estudio [De ratione studii, $15 \mathrm{II}$ ] (Erasmo, 1964: 45I $)^{6}$. Igualmente, Erasmo es consciente del papel que el método didáctico debe jugar en el aprendizaje de las lenguas, identificando en los niños su gran capacidad para aprenderlas, tanto las clásicas como las modernas, y de ahí el interés de aprovechar esta edad para iniciarlos tempranamente en su aprendizaje. La adecuada comprensión del término aprendizaje conlleva el uso de métodos y estrategias para lograr dicho objetivo. Tan interiorizado tiene Erasmo la importancia del método/s como facilitadores del aprendizaje, que toda esta obra está escrita y pensada desde el método (Erasmo, 1964: 45I-452). Ello explica su propuesta de utilizar como recurso una carta escrita en lengua vulgar para ser traducida al griego o al latín o a las dos. Erasmo con este ejercicio que propone está, además, indicando el peso que le otorga a la lengua vernácula como lengua hablada e instrumento generalizado de comunicación (Erasmo, 1964: 45I-452).

Erasmo le concede, pues, gran importancia a lo que podemos llamar la cuestión didáctica y a los métodos didácticos más adecuados para materializar esta orientación del aprendizaje. Prueba de ello es que buena parte de sus obras está marcada por dicho carácter. Este es el caso, por ejemplo, de dos de sus obras, cuyos contenidos son los proverbios y las sentencias como recursos que facilitan el aprendizaje de la cultura humanista y de la lengua latina. En la primera de ellas, Adagios (1500) 7 , Erasmo presenta una colección de 838 proverbios, recogidos en las obras de los autores clásicos (grecolatinos) y que utiliza en sus clases de retórica para hacer accesibles los textos clásicos. Desde su perspectiva, la brevedad y la concisión de los textos, así como su originalidad, familiarizaban a los estudiantes con los textos clásicos y les ayudaban a mejorar y embellecer el discurso. El gran éxito que tuvo esta obra se explica por las 122 ediciones que se hicieron de la misma, incrementándose significativamente a lo largo de las mismas el número de proverbios, que pasó a ser 4.I4I. La segunda obra en la que Erasmo utiliza el recurso didáctico de las sentencias y de los proverbios es Disticha catonis (I513), con el mismo título de la obra que se atribuye a Catón en el siglo iII a. C. y cuyo contenido es una colección de máximas morales y didácticas. La contribución de Erasmo a la obra de Catón consistió, fundamentalmente, en hacerle comentarios desde una perspectiva de humanista cristiano, en introducir correcciones y en publicarla en un solo libro ${ }^{8}$. Estas aportaciones de Erasmo ayudaron mucho a su difusión en escuelas y universidades (González-Blanco, 2007: 24).

6 Erasmo expone las ideas principales de su Plan de Estudio para los discípulos, en el escrito que le dirige a Pedro Viterio, profesor eximio de disciplinas liberales, como respuesta a su carta en la que le ruega que le señale el orden, el camino y la forma de los estudios para los estudiantes de buenas letras. Dicha texto está contenido en las Obras Escogidas de Erasmo y traducidas por Lorenzo Riber, en la parte que titula Miscelánea de Opúsculos juveniles (Erasmo, 1964: 444-458).

Cf. una edición española de esta obra en Erasmus, Desiderius: Adagios del poder y de la guerra y Teoría del Adagio, edición de Ramón Puig de la Bellacasa, Madrid, Alianza Editorial, 2008.

8 Esta obra cuenta con una edición bilingüe en latín y español a cargo de Antonio García Masegosa, 1997 . 
La preocupación de Erasmo por el aprendizaje, la cuestión didáctica y los métodos didácticos también está muy presente en otras de sus obras, como $D e$ copia verborum rerum (1512), Coloquios familiares (1518)9 y De conscribendis epistolis (I522). La primera de ellas, De copia verborum rerum, fue escrita durante su estancia docente en Cambridge y pensada como manual de estudiantes para mejorar el estilo, utilizando variedad de expresiones y temáticas. En la segunda obra, Coloquios familiares, Erasmo plantea, en su primera versión de I5I8, estrategias didácticas para facilitar el aprendizaje y la comunicación, así como las mejores formas de enseñar el latín a niños y jóvenes, utilizando la estrategia de fórmulas latinas de bello lenguaje que los alumnos deberían aprender para aumentar su bagaje lingüístico y facilitar su conversación. Este texto, en definitiva, no es más que un manual con finalidad docente que Erasmo utiliza durante su estancia en París para fomentar la conversación latina. Sin embargo, el texto resultante de la última edición de los Coloquios de 1533 sobrepasa el objetivo de la primera edición ya que «sin perder nunca del todo su condición inicial de texto didáctico, se irán convirtiendo cada vez más en una obra de crítica y educación moral y religiosa, $\mathrm{y}$, al mismo tiempo en un gran fresco de la vida cotidiana de la época» (Bayod y Parellada, 2oII: XCVIII). En la tercera obra, De conscribendis epistolis, Erasmo nos muestra, una vez más, sus dotes didácticas y los métodos didácticos más convenientes, aprovechando el recurso de cómo se deben escribir las cartas.

\section{I.2. Erasmo y su propuesta de Plan de estudio (De ratione studii, I5II)}

Las dos ideas fuertes que soportan y orientan el Plan de estudio de Erasmo para los discípulos son la lengua y el aprendizaje de esta, a través de aquellos métodos didácticos que resultan más convenientes, tal como se ha expuesto anteriormente.

Consecuencia de la orientación que, en opinión de Erasmo, debe tener el Plan de estudio, es el papel central que le asigna a la Gramática para el aprendizaje de la lengua (Erasmo, 1964: 445). No pasa desapercibida para Erasmo la importancia que tiene para la enseñanza y, especialmente, para la enseñanza de la gramática, el disponer de buenos maestros/preceptores, o en su caso de utilizar textos para el aprendizaje de los mejores autores (Erasmo, 1964: 445). El Plan de estudio que propone Erasmo no se limita a señalar la importancia que tiene la parte teórica, en la que el maestro es el protagonista, sino que también indica la relevancia de la práctica en el aprendizaje de los alumnos, leyendo a algún autor y ejercitando la práctica de hablar y escribir (Erasmo, 1964: 449-450).

Erasmo organiza el proceso de aprendizaje con la finalidad de obtener, en primera instancia, conocimientos básicos e iniciales. Pero, en un segundo momento, Erasmo con buen criterio entiende que la progresión del aprendizaje requiere la

9 Además de la edición de Lorenzo Riber de esta obra (1964), son de interés las ediciones españolas de Alonso Ruiz de Virués (siglo xvi), Barcelona, Anthropos, 2005 y la de Pedro Rodríguez Santidrián, en Erasmo de Rotterdam, Madrid, Gredos, 201 . 
adquisición de conocimientos más altos a través de contenidos y ejercicios prácticos distintos. A tal fin propone, por una parte, ejercitarse en los temas que ofrezcan a los alumnos información útil que les facilite alcanzar un nivel más alto de conocimientos (Erasmo, 1964: 450); pero, por otro lado, Erasmo aconseja también seguir haciendo prácticas más complejas de expresión y de escritura para que ayuden a la consecución de conocimientos más altos (Erasmo, 1964: 45I).

Una vez que los alumnos han madurado en sus conocimientos teóricos y prácticos del lenguaje, Erasmo recomienda la enseñanza de la gramática superior, que deberá hacerse con progresividad y con método, así como ejercitarse en la lectura de autores más graves y en lecturas más difíciles. Este paso constituirá un eslabón exigente en la cadena de aprendizaje que permitirá obtener un buen conocimiento del lenguaje (Erasmo, 1964: 45I). Igualmente, el trabajo creativo, en opinión de Erasmo, estimula el conocimiento de la lengua, facilitando así el aprendizaje de esta en aquellos aspectos o partes que resultan más complejos. Es conveniente activar todos los resortes personales que incentivan la disposición a aprender mediante el uso de aquellos instrumentos y caminos que se consideren los más idóneos para tal fin. Por ello, Erasmo en su escrito del Plan de estudio anima a los preceptores a trabajar en esta dirección (Erasmo, 1964: 452).

Como resultado del buen aprendizaje de la lengua, el propósito de Erasmo no es solo utilizarla correctamente, sino usarla de modo elegante. Por ello su referente serán aquellos autores latinos que mejor y más elegantemente han manejado la lengua latina y que han aportado mayor riqueza en cuanto a las formas gramaticales (Erasmo, I964: 446-447). Pero, además, dicho uso elegante de la lengua está relacionado con el estilo con que esta se construye, porque -a juicio de Erasmo- no basta con decir correctamente las cosas, sino que importa mucho cómo se dicen, el estilo con que se articulan las palabras y, en definitiva, cómo se construye el lenguaje. El conjunto de la obra de Erasmo refleja esta preocupación y no escatimó ningún esfuerzo por trabajar en esta dirección. Ello explica que también en este aspecto sus referentes latinos fueran aquellos autores que mejor respondían a este modelo de escritura y que una de sus grandes preocupaciones fuera transmitir a los que enseñan y escriben el valor que tiene el estilo en el uso del lenguaje (Erasmo, 1964: 447).

El estudio de la lengua no lo reduce Erasmo a su aprendizaje y a su buen uso, tal como nos lo describe en su obra Ratio studii, tal como se acaba de ver. También le interesa presentarnos la lengua desde otras perspectivas, como puede ser la fisiológica, la moral y la teológica ${ }^{\mathrm{io}}$, tarea que realiza en su obra De lingua (I525)

1o En opinión de Chaparro: «Erasmo no escribió ninguna obra en la que pretendiera abordar el problema de la lengua en su integridad, como hicieron otros humanistas. Prefirió tratar de forma discursiva diversos problemas aislados: el aprendizaje de las lenguas por parte de los niños (De pueris instituendis), los procedimientos para mejorar la expresión escrita (De duplice copia verborum ac rerum), cómo se deben escribir las cartas (De conscribendis epistolis), etc.» (CHAPARro, 2007: 2I, nota Io).

" La edición española de De Lingua de Erasmo que se utiliza en el texto es la preparada por Mañas y Merino, 2007. Hay otra traducción española de De Lingua de Bernardo Pérez de Chinchón, edición de Dorothy S. Severin, 1975. 
que dedicó a un noble polaco, Szydlowiecki, protector del humanismo, y cuya redacción responde, posiblemente, a la situación personal que rodea a Erasmo por estos años.

Erasmo incide en la perspectiva fisiológica de la lengua, haciendo toda una serie de reflexiones que señalan la importancia que tiene este órgano físico en el cuerpo humano como instrumento de comunicación. Al respecto, recuerda reiterativamente en el texto el valor que tiene el buen uso de la lengua como instrumento de comunicación, ya que, según él, esta puede ser bien o mal usada y es importante saber bien gobernarla y regirla (Erasmo, 2007: II6). Las consecuencias morales que se derivan del mal uso de la lengua son un aspecto o perspectiva que Erasmo tiene también presente (Erasmo, 2007: I2O-I2I), para concluir mostrando -en tanto que humanista cristiano-, la relevancia que tiene la perspectiva teológica de la lengua:

Por ello, si nos revestimos realmente de Cristo, si con el bautismo nos despojamos realmente del viejo hombre y de sus actos y nos revestimos del nuevo hombre, que fue creado según el ideal de Dios, ¿por qué aún permanece en nosotros aquella vieja lengua? Me refiero a la lengua fútil, charlatana, arrebatada, mentirosa, agria, pendenciera, difamadora, delatora, murmuradora, impúdica, perjura, que aconseja el mal, impía y blasfema. Si realmente hemos bebido el espíritu de Cristo, o si realmente somos miembros de Cristo, pues el Espíritu tiene conocimiento de toda palabra, ¿por qué no se oye en nosotros una lengua sobria, parca, moderada, púdica, reflexiva, verídica, mansa, pacífica, bienhablada, simple, suplicante, consoladora, exhortadora, confesante y agradecida? (Erasmo, 2007: 390-39I).

\section{I.3. El uso de las lenguas en el Plan de estudio}

El Plan de estudio que propone Erasmo a su amigo Pedro Viterio señala claramente cómo las lenguas latina y griega deben ser las lenguas a través de las que se enseñe la gramática para el aprendizaje del lenguaje. Y esta vía debe seguirse desde el inicio, desde el momento en que se inicia a los niños en la enseñanza (Erasmo, 1964: 445). Las razones de la conveniencia del uso de las dos lenguas, señala Erasmo, está en la proximidad de ambas lenguas y de que en estas se contiene todo lo que es necesario aprender. No obstante, Erasmo le da prioridad al uso de la lengua latina, como instrumento de aprendizaje y de comunicación, criterio que llevó a cabo en su propia práctica al utilizar el latín en su abundante producción científica.

Todas las orientaciones que contiene el Plan de estudio de Erasmo en relación a las lenguas van en la dirección del conocimiento de las lenguas clásicas, la latina y la griega, a través de cualificados preceptores en dichas lenguas y buenos textos de autores latinos y griegos. El aprendizaje y el conocimiento de las lenguas vernáculas no es objeto de consideración específica en dicho texto. Solamente hay dos referencias a dichas lenguas vernáculas en el mismo. En primer lugar, cuando Erasmo habla del conocimiento del nombre de las cosas menciona su etimología y su relación con las lenguas vernáculas (Erasmo, 1964: 448-449). En segundo lugar, 
cuando se refiere al método a seguir en el aprendizaje de la lengua, Erasmo considera útil la versión de textos-carta en lengua vernácula al latín o griego o a ambas lenguas (Erasmo, 1964: 45I).

No cabe duda, que Erasmo, al no valorar las lenguas vernáculas, no se dio por enterado, al menos oficialmente, de algunas considerables aportaciones que se estaban produciendo en aquel momento al mundo de las letras, por la vía de las literaturas modernas, en general, y de la literatura religiosa, en particular (Halkin, 1971: 89-90). Sin embargo, al estar supeditada su vocación de filólogo a su vocación de hombre de fe, el uso de las lenguas fue para el humanista holandés un instrumento para el conocimiento de Cristo. Desde esta perspectiva, el uso de las lenguas clásicas es mucho mejor; pero si, como mal menor hay que recurrir a las lenguas vernáculas para acceder a la fe de Cristo y fomentar la espiritualidad cristiana, bienvenido sea también dicho uso. Por tanto, por encima de sus principios en el uso de las lenguas, en Erasmo se impone el sentido práctico, al defender siempre el uso de las lenguas clásicas como bien superior, pero también el de las lenguas vernáculas, si es la única vía para acceder al conocimiento de Cristo (Erasmo, 1971: 454-455).

\subsection{Juan Luis Vives y el aprendizaje de las lenguas}

La contribución de Vives a una propuesta de Plan de Estudios se contiene, especialmente, en las dos cartas que escribió con los nombres De ratione studii puellarum y De ratione studii adolescentum. La primera fue escrita en 1523 (Oxford), a petición de doña Catalina, reina de Inglaterra, quien le solicitaba un breve plan de estudios para entregar al preceptor de la formación de su hija, la princesa María (Villalpando, 1984: 299). La segunda carta data del mismo año que la primera (Londres, I523) y el destinatario fue Carlos Montjoy, hijo de su amigo Guillermo, para orientarle a la iniciación de los estudios en la edad de la adolescencia (Villalpando, 1984: 313). Ambas cartas constituyen una unidad y fueron publicadas con el título común de Pedagogía pueril, en la primera versión castellana de las Obras completas de Juan Luis Vives por Lorenzo Riber (I947).

El Plan de Estudios que propone Vives, tanto para la edad pueril como para la adolescencia, hay que relacionarlo estrechamente con su importante obra De Disciplinis (Brujas, I53I) que dedica a Juan III, rey de Portugal y, muy especialmente, con la segunda parte de esta obra que se ha llamado Tratado de la enseñanza y en la que «se trata del arte de enseñar». Pero es más, dado que el tema de la educación es un referente permanente en toda la producción científica de Vives, el Plan de estudios que propone hay que leerlo en el contexto de toda su obra general.

\subsection{Lenguaje y lenguas en Juan Luis Vives}

Juan Luis Vives se desarrolla en los primeros años de su vida en un clima lingüístico plural. El castellano y el valenciano forman su bagaje lingüístico natural, 
aparte de su temprano aprendizaje del latín. El destino que le esperaba, Francia, Países Bajos e Inglaterra, le permitiría incorporar también de forma bastante natural el francés, flamenco e inglés, además del buen dominio del latín y buen conocimiento del griego. Por tanto, estamos ante un humanista que practicó con su ejemplo el uso de las lenguas, clásicas y vernáculas, entendiéndolas como instrumento lingüístico y forma de comunicación cultural. En cuanto a este aspecto, Vives adoptará una posición más abierta y funcional que Erasmo. Aunque ambos valoran el latín como la lengua por excelencia haciendo un uso exclusivo de la misma en sus escritos, sin embargo, la referencia a las lenguas vernáculas en Vives es mucho mayor que en Erasmo. Posiblemente, la diferencia de edad entre uno y otro, veinticinco años mayor Erasmo que Vives, explique tal situación, ya que en este cuarto de siglo muchas cosas cambiaron, entre otras, la implantación de las lenguas vernáculas iba extendiéndose y consolidándose (Monreal, 20II: I08-I09).

Vives no solo será un usuario de las lenguas, sino que se ocupa de las mismas en sus escritos, reflexionando acerca de la lengua en general y proponiendo metodologías para su aprendizaje. En las muchas y variadas reflexiones que Vives hace en su escritos a propósito de las lenguas y de la lengua, el valenciano plantea una cuestión de carácter general que consideramos de gran utilidad e, incluso, de actualidad: el conocimiento de las lenguas es algo que no se agota en sí mismo, sino que son un medio que nos sitúa a las puertas de las artes, de las disciplinas y de los saberes. La necesidad de las mismas hay que entenderla, según Vives, desde esta perspectiva, tal como lo expresa en su obra De Disciplinis.

El uso de las lenguas clásicas. La lengua latina era para Vives la lengua por excelencia. Ello explica que tanto él como Erasmo escribieran toda su amplia obra en latín y, además, en el latín del humanismo. Esta situación le vino impuesta, ya que el latín -pese a que las lenguas vernáculas en este tiempo empiezan a ganar terreno- $-^{12}$, era la lengua oficial en las universidades y en toda la producción científica que se generaba en ellas o en su entorno. Con el aprendizaje que Vives adquirió de esta lengua en su formación inicial de Valencia, su ciudad natal, y el perfeccionamiento que consiguió en su segundo periodo parisino de formación, logra hablar y escribir un latín perfecto (Fontán, 1992: 27).

El conocimiento teórico y práctico que Vives tiene de la lengua latina no obedece ni a la casualidad ni a la pura funcionalidad y utilidad. Hay un plus adicional que le lleva a hablar y escribir en latín como una segunda lengua materna: el espíritu del humanismo (Fontán, 1977: 42). Esta forma de pensar le hará a Vives vincularse tan fuertemente con toda la tradición clásica latina y, muy especialmente, con la obra de Cicerón, con Valla, con Nebrija y con Erasmo, entre otros. Por todo ello, el latín será para Vives la lengua en la que se expresa la cultura que respira y será su instrumento habitual para la escritura, la lectura y el pensamiento (Esteban, 1997: 10). Declararse admirador de Cicerón, como eran Vives y Erasmo, quería decir imitarlo en lo imitable, pero no cuando se trataba de abordar cuestiones que habían cambiado con el paso del tiempo transcurrido (Núñez,

i2 C $f$. Riber en Vives, i947: 40, tomo i y Moreno, 2006: 163. 
1993: 46-53). Ambos consideraban que el latín era una lengua literaria creativa y no muerta, y por ello la usaron. Pero el empleo literario creativo que de ella hicieron les llevó a escribir con sentido de la tradición clásica, pero también con flexibilidad y actualidad.

Independientemente de que para Vives el latín fuera su lengua clásica principal, tampoco descuidó el conocimiento del griego y la posibilidad de acceder a las fuentes originales escritas en esta lengua, demostrando a lo largo de sus escritos tener de dicha lengua un buen manejo.

\subsubsection{Lengua y las De ratione studii en Juan Luis Vives}

Los textos De ratione studii (Plan de estudio) que propone el valenciano, tanto para la edad pueril (De ratione studii puellarum) como para la adolescencia (De ratione studii adolescentium), son dos cartas en las que ofrece consejos para orientar los estudios en la niñez y la adolescencia. Ambos textos no hacen sino reflejar la importancia que Vives otorga a la lengua en el sistema de enseñanza. Su conocimiento, en su opinión, facilita el acceso al saber y forma parte de la cultura humanista; razón por la que el aprendizaje de las lenguas constituye una pieza fundamental en la enseñanza.

El latín, en opinión de Vives, debe ser la lengua central y principal que utilice el sistema de enseñanza, dándole prioridad en su aprendizaje al de otras lenguas, tanto clásicas como vernáculas. Por ello, los textos De ratione studii $i^{13}$ en los que Vives ofrece un breve plan de estudio, se ocupan del latín y no de otras lenguas.

En el caso de De ratione studii puellarum, Vives indica una serie de preceptos o recomendaciones a seguir en la enseñanza del latín. Con el fin de conseguir dicho objetivo, Vives recomienda también el uso de la lengua vernácula materna del alumno para que sirva de apoyo en la enseñanza del latín (Vives, 1984: 306). La mención, por tanto, que hace Vives a las lenguas vernáculas en este plan de estudio no es para que estas sean objeto de estudio específico, sino para que sirvan de instrumento en el aprendizaje del latín. Vives da por sentado que la lengua materna es vernácula y la que debe ser objeto de estudio es la latina.

En el caso de De ratione studii adolescentium, Vives ofrece también una serie de preceptos o recomendaciones a seguir en la enseñanza del latín, en este caso, para los adolescentes. En esta segunda carta los preceptos o recomendaciones se amplían respecto a la primera, ya que están orientados a adolescentes que tienen más capacidad de aprendizaje. De entre dichas orientaciones, hay una que conviene tenerse en cuenta por su importancia en la organización del sistema de

${ }_{13}$ Los dos textos de las mencionadas cartas fueron publicados por Lorenzo Riber bajo el título de Pedagogía Pueril, en la única versión castellana de las Obras Completas de Vives por Lorenzo Riber (Vives, 1948). Los textos de las citas de las dos cartas de Vives están tomados de la edición parcial de las Obras Completas de Vives (versión Riber) llevada a cabo por José Manuel Villalpando en 1984 y en la que realiza un Estudio Preliminar y los Prólogos de las mismas, razón por la que se ha usado esta edición. 
enseñanza y que debe reflejarse en el plan de estudio a seguir por los adolescentes: el aprendizaje del griego, juntamente con el latín. Vives considera que los adolescentes tienen capacidad para ser instruidos también en la lengua griega, con lo que tendrían acceso al saber a través del conocimiento de las dos lenguas clásicas fundamentales (Vives, 1984: 321-322).

De nuevo, en esta segunda carta, Vives hace mención del uso de las lenguas vernáculas. Da por sentado que estas constituyen la vía comunicativa común y que se constituyen en instrumentos para el aprendizaje de las lenguas clásicas, especialmente del latín. Incluso recomienda el uso de las lenguas vernáculas, cuando pueda hacerse un uso incorrecto del latín (Vives, 1948: 329-330, tomo II). No obstante, el reconocimiento que Vives hace de la utilidad del uso de las lenguas vernáculas en relación a las clásicas no le lleva a incluir en su Ratio Studii, plan de estudios, el aprendizaje de las mismas. Solamente contempla el latín y el griego como lenguas a aprender formalmente en el sistema de enseñanza. Las vernáculas las sitúa fuera de sistema formal de enseñanza.

3.2.3. El tratado De disciplinis de Vives y el aprendizaje de las lenguas vernáculas

La obra De disciplinis, en su Segunda parte titulada «en que se trata del arte de enseñar» (Tratado de enseñanza, como se le suele llamar) ${ }^{\text {t4 }}$, Vives habla de modo más específico que en sus dos cartas mencionadas anteriormente sobre el uso que conviene hacer de las lenguas vernáculas en el sistema de aprendizaje, concretamente en el libro tercero denominado La enseñanza de los idiomas. Las recomendaciones que Vives hace al respecto son las siguientes: cuidar que los niños pronuncien bien el idioma patrio, tanto en familia como en la escuela (Vives, 1984: 4I); extender al máximo el estudio de las lenguas vernáculas para acceder al conocimiento religioso (Vives, 1984: 42); el maestro debe conocer perfectamente la lengua nativa de los niños (Vives, 1984: 47); el profesor debe utilizar al principio el idioma vernáculo (Vives, I984: 47); hablar simultáneamente la lengua vernácula y la lengua latina (Vives, I984: 50).

No cabe duda de que estas recomendaciones de Vives trasmiten perfectamente su pensamiento acerca del uso de las lenguas vernáculas en el sistema de aprendizaje, tanto formal como informal; es decir, tanto en la escuela como fuera de ella. Estas orientaciones no constituyen en sentido estricto una Ratio studii, aunque sí se las pueden considerar, en sentido amplio, como directrices que deben ser tenidas en cuenta, según Vives, en la organización de los estudios, especialmente los relativos a los niños y adolescentes. Consecuencia del pensamiento de Vives

${ }^{14}$ La edición parcial de las Obras Completas de Vives (versión Riber), llevada a cabo por José Manuel Villalpando en 1984, así denomina esta Segunda Parte (Tratado de la Enseñanza), cuyo contenido lo clasifica, siguiendo a Foster Watson en una traducción inglesa, en seis libros o apartados, con las siguientes denominaciones:.$^{\circ}{ }^{\circ}$ Los orígenes de la educación; $2 . .^{\circ}$ Las escuelas; $3 .^{\circ}$ La enseñanza de idiomas; $4 .^{\circ}$ Las disciplinas superiores; $5 .^{\circ}$ Los estudios y la vida; y $6 .^{\circ}$ De la vida y de las costumbres del erudito (Villalpando, 1984: 3-4). 
JUAN LUIS MONREAL PÉREZ

en relación al uso de las lenguas vernáculas, este marca un claro avance, ya que las tiene muy en cuenta para dar pautas orientadoras del sistema de enseñanza; este avance también se produce respecto a lo que fue, por ejemplo, la posición de Erasmo (Calero: 2009).

\section{Ignacio de Loyola, Melanchthon, Calvino y las Ratio studiorum}

El desarrollo del siglo xvi supuso, en el aspecto cultural, la consolidación del Humanismo renacentista y, en el aspecto religioso, la emergencia de la Reforma y Contrarreforma en la Iglesia, impactando ambos movimientos religiosos en todos los ámbitos de la vida, pero, especialmente, en el campo de la educación a través de la organización del sistema de enseñanza con las correspondientes Ratio studiorum y de las que fueron actores principales Ignacio de Loyola, por el lado de la Contrarreforma, y por el lado de la Reforma, Melanchthon y Calvino. Veamos, a continuación, la contribución de cada uno de ellos al sistema de enseñanza de su tiempo que tuvo influencia, sin lugar a duda, en el pensamiento y en la organización de los estudios, tanto de aquel momento como posteriormente.

4.I. Ignacio de Loyola y la Ratio studiorum de los jesuitas

Tres son los aspectos que interesa examinar al analizar la Ratio studiorum de los jesuitas: la educación, la formación y la lengua.

\section{I.I. Educación y Studia humanitatis}

Para Ignacio de Loyola (I49I-I556) el hombre y la educación constituyen dos objetivos centrales en su vida (Labrador, 20I3: 70). En ello influyen la época en que vivió, la cultura humanista dominante de la que participó, la formación que recibió y su visión cristiana de la vida (Vergara, 2007: 172). A lo largo de todo el itinerario personal, formativo, profesional y religioso que Ignacio de Loyola recorre, dichos objetivos e intereses van tomando protagonismo en su vida, teniendo un peso especial en ello su larga estancia en París ( 7 años), después de pasar por las universidades de Alcalá y Salamanca, que contribuirá a imbuirse del clima de la cultura humanística renacentista y, por ende, a revalorizar el hombre y la educación, como los dos objetivos principales en su vida. Será en la Universidad de París donde Ignacio tiene la ocasión de conocer y familiarizarse con personajes relevantes del momento y de la cultura humanista cristiana como Erasmo, Vives y Montaigne (Labrador, 1999a: 26) y que tanto le influyen en su pensamiento y en los proyectos que más tarde desarrollará. Especialmente, desde la perspectiva jesuítica, se ha considerado siempre a Erasmo cercano a los problemas de la espiritualidad y de la pedagogía jesuítica (Batllori, 1990: II7). 
Igualmente, Ignacio de Loyola, a través de su itinerario de vida y de su proyecto religioso, se cruzará en el camino con Lutero y Melanchthon, con el Reformismo religioso y, especialmente, con el proyecto de la Reforma protestante sobre la enseñanza. No cabe duda de que las fuertes diferencias teológicas que existieron entre ellos no impidieron que tuvieran una especial cercanía en el ámbito de la educación, al compartir una concepción humanística de la misma que se tradujo en una semejante aplicación y desarrollo de los Studia bumanitatis (García, 2003: II5) ${ }^{\text {I5 }}$.

\section{I.2. Enseñanza y la Ratio studiorum}

El interés de Ignacio de Loyola por el hombre y la educación se materializará a través de su proyecto de creación de la Compañía de Jesús y de la orientación pedagógica que finalmente le imprime. Si bien es verdad que, al inicio de su empresa religiosa, Ignacio de Loyola solo tenía decidida la filosofía general de la misma, es decir, la evangelización del mundo, bien pronto -sin embargo-, la actividad educativa se constituirá en un objetivo prioritario de dicha empresa a través del apostolado a realizar en los colegios que va fundando (Codina, I968: Ix). La enseñanza, por tanto, será el instrumento que facilitará al hombre una visión cristiana al ofrecerle una educación fundamentada en principios morales y religiosos (Labrador, I999a: 24), y será la razón por la que Ignacio de Loyola dedicará buena parte de su tiempo y de sus recursos a dicha actividad.

Ignacio de Loyola, como hombre de su tiempo y desde los valores que orien$\tan$ su vida, no entiende otra enseñanza que no sea la inspirada por el humanismo imperante en el siglo xvi y por los valores cristianos que profesa. Desde dicha perspectiva humanista cristiana, la formación humana debe estar orientada, por una parte, por los cánones renacentistas y, por otra, por los valores morales y religiosos (Albistur, 2017: 69-70).

A la hora de pensar en la organización de la enseñanza, la Ratio studiorum, tanto en contenidos como en metodología de aprendizaje, Ignacio de Loyola se ve influido por lo que ha aprendido y experimentado en su etapa formativa en la Universidad de París (Vergara, 2007: 190-197), donde los estudios se estructuraban en tres ciclos de formación lingüística, filosófica y teológica, y en donde los métodos de aprendizaje se caracterizaban por su orientación práctica (Labrador, I999b: II9). Dicha formación, junto a su trayectoria vital y la visión humanística que tiene del hombre, constituyeron los ingredientes fundamentales de su filosofía de la enseñanza que plasmó en la organización del sistema educativo que se ha venido en llamar la Ratio studiorum de Ignacio de Loyola o de la Compañía de Jesús, verdaderamente influenciada por el modelo educativo y pedagógico del llamado modus parisiensis (Codina, 1968: 147-150).

is Desde la perspectiva protestante, aunque no se califica a Ignacio de Loyola como un humanista total, sin embargo, sí se le considera como tal en el campo de la enseñanza, al haber contribuido a su renovación desde la visión de los studia humanitatis (MARON, 200I: I23). 
La visión o filosofía de la enseñanza de Ignacio de Loyola se ve materializada en dos escritos que reflejan su pensamiento al respecto y constituyen los fundamentos educativos que soportan la labor educativa que la Compañía de Jesús ha desarrollado desde el inicio de su fundación hasta la actualidad. Nos referimos, concretamente, a Los Ejercicios Espirituales y a La Parte IV de las Constituciones; en ambos documentos están presentes tanto la filosofía como la metodología y la logística que articulan la llamada Ratio studiorum de los jesuitas (Espino, 2005: 57). No cabe duda de que la propuesta metodológica que Ignacio de Loyola hace en los mencionados documentos está impregnada de sentido pedagógico (Rambla, 2008: 8), y se refleja en la misma la formación académica que Ignacio de Loyola recibe en la Universidad de París, así como su propia experiencia de aprendizaje en la que el diálogo pedagógico tuvo su relevancia. Por ello, se puede decir que Los Ejercicios Espirituales y La Parte IV de las Constituciones aportan, por una parte, las reflexiones más significativas de Ignacio de Loyola en materia de enseñanza y, por otra parte, están en el origen de lo que se ha llamado la Ratio studiorum jesuítica para denominar las diferentes propuestas de organización de la enseñanza y de modelos pedagógicos (Bertrán, 1984: 5 y Revuelta, 1983: 365 y ss.) que se han hecho a lo largo de la existencia de la Compañía de Jesús y que han conformado el llamado sistema educativo jesuítico.

En el largo y debatido proceso de elaboración de las diferentes Ratio studiorum existentes, hay que sumar a la propia contribución de Ignacio de Loyola y del grupo de compañeros que desde el inicio le siguieron en el proyecto jesuítico ${ }^{16}$, otras contribuciones que tienen lugar en tiempos de Ignacio de Loyola $^{17} \mathrm{o}$ inmediatamente

16 Por razones de espacio no es posible detallar todas las aportaciones que hacen al proyecto pedagógico de Ignacio cada uno de los compañeros que le acompañan desde el inicio. Sin embargo, y a modo de ejemplo, conviene señalar, especialmente, las contribuciones del español Jerónimo Nadal «homme de confiance d'Ignace de Loyola en matière d'études, "expert en Collèges” incontesté, organisateur du réseau scolaire de l'Ordre, c'est lui qui a mis au point et répandu par toute l'Europe le système d'éducation propre à la Compagnie de Jésus. C'est lui qui a créé à Messine le Collège qui a servi de prototype à tous les autres Collèges de lettres humaines des jésuites. C'est encore lui qui a élaboré les tout premiers programmes d'études de la Compagnie, qui ont constitué le noyau de la future Ratio studiorum» (Codina, 1968: 347-348). También el francés Coudret fue un eficaz colaborador en dicho proyecto educativo. Ambos fueron compañeros de Ignacio y de estudio en París. Nadal, al estar ocupado en otras tareas por encargo de Ignacio, solicitó la colaboración de Coudret para trasladar a Roma, a petición del fundador de la Compañía, las experiencias docentes del Colegio de Mesina en relación al Plan de Estudios ( $C f$. Nadal Cañellas, 2007) del que fue Nadal su fundador (Codina, 1968: 256-336). El fuerte compromiso de Coudret con la docencia le llevó a elaborar el texto de gramática De primis latinae grammatices rudimentis libellus (I55I), siendo uno de los primeros escritos escolares jesuíticos. La aportación de Coudret a la gramática se vería completada un poco más tarde por la Summa latinae de Frusio (1556).

${ }_{17}$ Con el paso de los años y a medida que se va desarrollando el proyecto educativo jesuítico, existe un interés especial por uniformar los planes de estudio y los proyectos pedagógicos para todos los colegios jesuíticos. Resultado de este afán y esfuerzo serán los textos de Perpinyà De ratione liberorum instituendorum litteris graecis et latinis (1965); de Ledesma la Grammatica brevi et perspicua methodo comprehensa, ad usum Collegii romani Societatis Jesu (1569), y de Alvares De institutione grammatica libri III (I572) que, sin lugar a duda, contribuyeron a clarificar y ordenar el proceso de aprendizaje en los colegios de la Compañía de Jesús. En opinión de Rogelio Ponce de León «las 
posteriores, y que preparan el camino hasta la elaboración de una redacción final unificada de la Ratio studiorum de I599, materializada bajo la coordinación del padre Acquaviva y que serviría para orientar la enseñanza impartida por la Compañía de Jesús (Labrador, 2013: 72).

Sin embargo, la Ratio studiorum de 1599 no fue la última propuesta de organización de la enseñanza jesuítica; al contrario, a esta le siguió otra en el siglo XIX, concretamente la Ratio studiorum de I832, que modifica parte de la anterior, pero mantiene aquello que se considera como más fundamental, tal como la estructura, los principios y la metodología de la enseñanza. Este proceso de elaboración de nuevas propuestas de Ratio studiorum se da por cerrado a principios del siglo xx, en 1906, al decidirse por la Congregación General xxv no elaborar nuevas propuestas, sino aplicar la existente en cada nación o provincia, «según las necesidades y posibilidades de los tiempos, lugares y personas [...] manteniendo los principios esenciales de la pedagogía ignaciana de la Ratio» (Labrador, I999a: 44-45). Consecuencia de esta decisión y del trabajo de adaptación de la Ratio studiorum al caso de España, en 1986 la Compañía de Jesús publica en nuestro país el documento Las características de la educación de la Compañía de Jesús, que «no pretende ser una nueva Ratio, es un estudio perfectamente estructurado que recoge en sus nueve capítulos el modo de vivir hoy la concepción educativa de Ignacio de Loyola en los colegios» (Labrador, 1999a: 45). Es manifiesto que las diferentes Ratio studiorum que se han propuesto a lo largo del tiempo siempre han reflejado el pensamiento de Ignacio de Loyola sobre la enseñanza, su interés por el conocimiento experiencial y la comunicación educativa (Labrador, I999b: II8).

\section{I.3. Enseñanza de las lenguas en la Ratio studiorum de los jesuitas}

Ignacio de Loyola en la Parte IV de sus Constituciones explicita, siguiendo la tradición humanista renacentista, lo que debe ser el objeto de la formación en la enseñanza. Esta la organiza en dos niveles de enseñanza: el nivel superior, que comprende los estudios de las letras humanas, las artes o filosofía, la teología, las leyes y la medicina; y el nivel inferior, que comprende los estudios propedéuticos con la gramática y con la retórica o elocuencia, tanto oral como escrita (Labrador, I999a: 29-30).

El estudio de la gramática debe realizarse, en opinión de Ignacio de Loyola, en lengua latina, griega y vernácula, siendo esta última, como lengua materna que es, el instrumento lingüístico a utilizar para el acceso y el aprendizaje de las otras dos lenguas. Sin embargo, de estas tres lenguas serán las llamadas clásicas (latín y griego), y más concretamente el latín, el que ocupará el lugar central, siguiendo de nuevo Ignacio de Loyola la tradición humanista renacentista. Con esta elección, el jesuita

propuestas metodológicas que aparecen en el De ratione liberorurn instituendorum litteris graecis et latinis (de Perpinyà) y en los escolios de los De institutione grammatica libri tres (de Alves) fueron el resultado de años y años de experiencia pedagógica de los autores en los centros escolares lusos de la Compañía de Jesús» (Ponce De León, 2000: 252). 
vasco orientará la enseñanza, en definitiva, por la vía de las Humanidades clásicas, aunque priorizando aquellos textos y autores clásicos en la enseñanza menos marcados por la mentalidad pagana, como Quintiliano, Cicerón, Virgilio, Ovidio, Demóstenes, Crisóstomo y san Jerónimo (Labrador, 1999a: 29-30).

El pensamiento de Ignacio de Loyola acerca del uso de las lenguas y expresado en la Parte IV de las Constituciones, quedaría más tarde reflejado en la Ratio studiorum de I599 de los jesuitas y con ello se aseguraría el empleo de las lenguas en el sistema educativo de la Compañía de Jesús: por una parte, las clásicas y siendo el latín la lengua fundamental (Ratio Studiorum Oficial's, p. 3I); pero, por otra parte, la lengua vernácula se utilizará como instrumento lingüístico básico para el acceso y el aprendizaje de las lenguas clásicas (Ratio Studiorum Oficial, pp. Io6, I09, IIO, II2, II6).

\subsection{Melanchthon y la Ratio studiorum protestante}

Philip Melanchthon puede ser calificado como hombre eminente del $\mathrm{Hu}$ manismo renacentista y como figura luminosa que encarna el ideal de aquello que llamamos humanismo cristiano o, como decía de él Lutero, que no solo estaba llamado a la inmortalidad, sino que también merecía su inclusión en el canon de la Iglesia (Stroh, 20I2: 224 y 234).

La condición de Melanchthon como hombre reformador está relacionada con su condición de hombre humanista; aspectos estrechamente vinculados a su trayectoria de vida. Desde el inicio de su formación académica hasta su total compromiso con la Reforma protestante, en todo lo que escribe y hace, el espíritu humanista es una constante en su vida, al manifestarse de manera firme en su acción, la unión de lengua, razón y moralidad (Stroh, 2012: 237). Esto explica en Melanchthon su permanente compromiso humanista que se manifiesta tanto en su proceso formativo como en la elaboración de su pensamiento y en la intensa actividad que desarrolla, tal como puede verse en sus escritos tempranos que están marcados por el espíritu humanista (Rupp, 1996: 662).

\subsection{Humanismo y enseñanza en Melanchthon}

La etapa de Melanchthon como docente en la universidad de Tubinga, pese a su juventud, le permitió, por una parte, iniciar la elaboración de su pensamiento humanista ${ }^{19}$, pero también fue el punto de partida para la producción de materiales

18 Ratio atque Institutio Studiorum Societatis Jesu. Auctoritate Septimae Congregationis Generalis aucta. Antverpiae apud Joan. Meursium, I635, en $8 .^{\circ}$ (se trata de una reedición de la publicada en Roma en 1616). Traducción: Gustavo Amigó, S. J. La presente versión ha sido revisada por el Dr. Daniel Álvarez, S. J.

19 El discurso que pronuncia Melanchthon en la Universidad de Tubinga, De artibus liberalibus (I517), refleja el fuerte carácter humanista que reviste su propuesta de programa educativo. 
para la escuela, respondiendo así a las necesidades didácticas que la escuela reclamaba. Resultado de ello es la edición que hace de la obra latina de Terencio adaptada a los niños y las gramáticas de latín y griego, que tendrían un considerable éxito.

La llegada de Melanchthon a Wittenberg le permitió desarrollar su actividad docente orientándola claramente bajo el espíritu humanista. Un buen dato que confirma tal orientación fue que su primera lección universitaria ( 28 de agosto de I5I8) tuvo como objeto el tema de la Mejora de los estudios para los jóvenes [sobre la reforma educativa] (De corrigendis adolescentiae studiis), dejando con esto bien claro el espíritu humanista que la guiaba. Un tiempo más tarde, Melanchthon pronunció un memorable discurso titulado El Elogio de la elocuencia (Encomium eloquentiae), en el que defiende la importancia de este arte para bien expresarse; para la comprensión de textos, tanto clásicos latinos como bíblicos; para el estudio de lenguas, y, en definitiva, para la educación del espíritu. Ello explica que el espíritu humanista de Melanchthon sea el resultado de la combinación articulada de lengua, razón y educación moral/intelectual.

Por todo ello, Melanchthon, en lo fundamental, participaba de los principios que caracterizaban al movimiento humanista renacentista: retorno a las fuentes clásicas, defensa de las lenguas clásicas, crítica del degenerado uso que se hacía del latín e interés por los saberes que favorecían la modernización de la sociedad, tales como la historia, las ciencias naturales, las matemáticas (Labrador, 1984: I8). La razón humanista llevó a Melanchthon a pronunciarse por el no abandono de los estudios de las letras, tal como hizo en el texto De studiis literarum non deserendis (1548).

\subsubsection{Melanchthon y la organización de la enseñanza}

La política escolar, en general, es la que orienta la organización de la enseñanza o la Ratio studiorum; en el caso que nos ocupa, la Ratio studiorum de la Reforma protestante de Melanchthon. Fue precisamente en este ámbito en el que Melanchthon expresó, especialmente, su carácter reformador. Resultado de su preocupación y compromiso con la enseñanza es la producción de libros de texto que necesitaban las escuelas y las universidades en Alemania en todos los campos del saber, como gramática griega y latina, retórica, dialéctica, autores latinos, ciencias naturales, física, psicología, ética, etc. En general, sus obras ${ }^{20} \mathrm{y}$, especialmente, su Gramática latina (Grammatica D. Philippi latina cum exercitio) eran de óptima calidad didáctica, ya que desde un principio estaban concebidas para su uso académico y para ser utilizadas por profesores motivados. De hecho, se tiene constancia de que hasta 1757 dicha gramática se editó más de 200 veces y su uso era habitual en las escuelas, formando parte del Programa escolar de 1528

20 La producción científica de Melanchthon es amplia y la que conviene mencionar aquí son los textos Enquiridion elementorum puerilium y Cathechesis Puerilis, por su carácter didáctico. 
concebido por el propio Melanchthon (Kößling, 1999: 8I y 96). La expansión del uso de dicha obra en instituciones educativas convirtió a Melanchthon en el referente principal del mundo académico de su época, razón por la que se le conoce como «Praeceptor Germaniae».

La concepción reformadora que Melanchthon tuvo de la enseñanza, además de estar imbuida del espíritu humanístico, también se soportaba en la idea de que esta debía preparar para lo que la Iglesia y el Estado exigen del joven habitante y del joven ciudadano, siguiendo la línea de política educativa protestante alemana (Trölher, 20I3: 88), tal como Lutero y él mismo propusieron. Este enfoque práctico se constituyó en la base organizativa de la enseñanza en la nueva Iglesia protestante alemana de la que él era el máximo representante. Esta dimensión funcional y práctica explica, por una parte, el éxito de la ordenación escolar que puso en marcha y que materializó a través de los Reglamentos escolares; y, por otra parte, le hizo implicarse en experiencias educativas para fomentar formas diversas de aprendizaje. Un ejemplo de ello es la iniciativa que llevó a cabo con la creación de un pensionado -Schola domestica- (Faubell, I984: I2I) en su casa, donde preparaba a jóvenes, futuros universitarios, en materias diversas como latín, griego, hebreo, matemáticas, ética y física aristotélica.

Dada la alta responsabilidad que Melanchthon tuvo en la naciente Iglesia y su gran preocupación por la enseñanza y su didáctica ${ }^{21}$, le llevó a la elaboración de planes de estudio en escuelas y Universidades de Estados de Alemania (Faubell, 1984: I2I), entre los cuales conviene mencionar la Ordenación Escolar para el Electorado de Sajonia (I528). Dichos planes fueron estructurados en clases de leer y escribir, gramática y composición y en donde el latín se constituye en la lengua articuladora de los mismos (Faubell, 1984: I2I-I22). Se trata de planes de estudio determinados por el dominio de contenidos lingüísticos y no por la edad. En la práctica se quiere que jóvenes de diversas edades puedan experimentar la mejora conjunta de su formación lingüística, tal como se buscaba en la primera escuela (Schola Domestica), al modo de las Burse medievales (Kößling, I999: 76).

Melanchthon llevó a cabo el mismo modelo de reforma en las escuelas ya existentes o de nueva creación y en las que él intervenía directamente o indirectamente, como fueron el caso de las escuelas de Wittenberg (I520), Eisleben (I525) y Núremberg (1524) ${ }^{22}$. En todas ellas, Melanchthon busca conseguir una formación general y una instrucción intelectual, y ambas formaciones se transmiten teniendo en cuenta la vertiente de la educación religiosa (Labrador, 1984: 20). A tal fin, Melanchthon aplica todas las orientaciones que enuncia al conjunto de los elementos que conforman la organización de la enseñanza: profesores, padres, alumnos, contenidos, materiales y metodología. Las ligeras variantes que introduce en la

${ }^{21}$ La preocupación y el compromiso de Melanchthon de reformar la enseñanza en Alemania parte del conocimiento directo que tiene del sistema de enseñanza en los niveles no universitario y universitario. Conocimiento que le lleva a adoptar una actitud crítica ante la situación existente y que describirá en su escrito «De Misseriis Paedagogorum» (WoOdward, 1967: 217).

22 En el discurso que pronuncia en el acto de apertura de esta escuela con el título de In landem novae scholae (1526), Melanchthon renueva su apuesta por la reforma del sistema educativo alemán. 
aplicación del modelo de organización de la enseñanza responden a las particularidades que presenta cada una de las escuelas y que necesariamente tuvo que tener en cuenta para asegurar la viabilidad de la organización del sistema educativo (Labrador, 1984: 20-27).

El desarrollo y la estructuración que hace Melanchthon del qué y del cómo enseñar se ven orientados por su gran capacidad pedagógica (Hofmann: 1963), marcada esta por el uso amplio de los saberes; por la agrupación de los alumnos (3 grupos) según su nivel de conocimientos en busca de la máxima eficacia en la enseñanza, y por un claro carácter práctico en su estrategia docente, que le llevó a proponer el uso de métodos y técnicas didácticas, como el debate y la declamación (Stupperich, 1960: 56), con la intención de facilitar el aprendizaje. Melanchthon no escatimó los necesarios escritos a lo largo de su vida para seguir insistiendo en la reforma de los estudios con el fin de hacer el aprendizaje accesible a los jóvenes ${ }^{23}$.

Aunque Melanchthon dedicó buena parte de su actividad a la organización de las escuelas, no obstante, la reforma de la universidad formó también parte de sus preocupaciones. Al tiempo que realizaba la reforma de la enseñanza secundaria, fue reclamado su asesoramiento por varias universidades (Tubinga, Leipzig, Heidelberg, Marburgo, Koenisberg y, cómo no, Wittenberg, su propia universidad, que se constituiría en el modelo de referencia para la reforma) que querían acometer su transformación (Scheible, 1902: 139).

En definitiva, la filosofía de la educación que Melanchthon impulsa en la Alemania de la Reforma a través de la organización de la enseñanza, tanto en escuelas como en universidades, condujo a que los individuos aprendieran a articular sus pensamientos, sentimientos, sus experiencias de conocimiento científico y todo lo que les motivaba y preocupaba; es decir, a saber establecer la adecuada relación entre ciencia, cultura, religión y sociedad (Monreal, 2017: 219). Sin esta filosofía y perspectiva, hubiera sido difícil de explicar la emergencia de relevantes figuras pertenecientes a distintas áreas de conocimiento y que destacaron por su gran dominio de la lengua y por su deseo de unificar religión y cultura.

\subsubsection{La enseñanza de las lenguas en la organización escolar de Melanchthon}

Aunque el uso del buen latín constituía para Melanchthon un objetivo principal, dado que era un buen humanista, así como catedrático de Griego en la Universidad de Wittenberg, sin embargo, tuvo también una actitud positiva hacia el uso del alemán y hacia las lenguas vernáculas en general, ya que contribuían al conocimiento y al desarrollo de los saberes.

Todo lo que Melanchthon pensaba respecto a las lenguas y a su uso concreto era coincidente con lo que Lutero escribió al respecto en varios de sus escritos y

23 Este es el objetivo que pretende conseguir con algunos de sus escritos, bien utilizando recursos literarios como las fábulas (De utilitate fabulorum, I526), bien criticando el barbarismo científico que no ayuda a la orientación de la educación (De studiis adolescestium, 1929). 
cuyo pensamiento lo expresó, muy especialmente, en su obra $A$ los magistrados de todas las ciudades alemanas, para que construyan y mantengan escuelas cristianas, obra de carácter pedagógico y que escribió en I524 (Egido, 2006).

La preocupación de Melanchthon por las lenguas no es solo teórica. Al contrario, como responsable de la organización de la enseñanza en la Reforma, se preocupa de que las lenguas ocupen el espacio que les debe corresponder en la nueva enseñanza de la Reforma en Alemania, a través de los nuevos planes de estudio a implantar. Es consciente de que la debilidad del sistema de enseñanza en Alemania es la causa de las deficiencias en el conocimiento de las lenguas en el país. Por ello, la reforma del sistema de enseñanza que lidera, tanto el universitario como el no universitario, supondrá un impulso en la mejora del aprendizaje de las lenguas, a través del uso oral de las mismas, de las técnicas del diálogo, de las disputas y las declamaciones. Los campos de la filología (que constituyen el territorio de las lenguas) y de la filosofía son, en opinión de Melanchthon, los que fundamentan el conjunto de los saberes, incluido el teológico (Richard, 1902: 138).

Pero la preocupación fundamental de Melanchthon por mejorar el aprendizaje de las lenguas se focaliza, básicamente, en las lenguas clásicas ${ }^{24}$, especialmente en el latín, pero sin que esto suponga darle la espalda a las lenguas vernáculas, en este caso al alemán. Por ello, utilizó la lengua alemana para explicar el significado de las palabras y cada una de las particularidades lingüísticas de la lengua latina, tal como hizo en su obra Exercitium puerorum Gramaticale per dietas distributum $(\mathrm{I} 485)^{25}$.

El pensamiento de Melanchthon acerca de la lengua y de las lenguas no se reduce a mostrar su importancia y relevancia. Va más lejos que esto, ya que le preocupa mucho el uso didáctico de la misma, tal como anteriormente se ha señalado. Su estrategia didáctica de suplir la abstracción con la capacidad deductiva del alumno le permite introducir ejemplos de autores de la Antigüedad, como Terencio, Cicerón o Virgilio. De hecho, su gramática estaba orientada a su uso práctico en la clase de latín, en la que los estudiantes hacían la lectura de dichos textos, y se les inculcaba el uso oral y escrito de la lengua.

El propio pensamiento de Lutero sobre la reforma de la enseñanza es básicamente el pensamiento que Melanchthon traslada a la organización de la enseñanza en la Reforma en la que siempre acentuó su orientación didáctica y en la que incorporó aquellos nuevos aspectos que resultaban relevantes para el aprendizaje de la juventud, entre los que se encuentran el aprendizaje y el uso de las lenguas, no solo clásicas, sino también las vernáculas.

${ }^{24}$ Varios de los escritos de Melanchthon van dirigidos a subrayar la importancia del conocimiento de las tres lenguas clásicas: el latín, el griego y el hebreo, como forma de acceder al conocimiento de las fuentes. Con carácter específico, el escrito De studio linguarum (I533) hace hincapié en la necesidad del conocimiento tanto del griego como del latín. En otros textos como la Ratio discendi (I522) y De studiis linguae graecae (I549), Melanchthon muestra la necesidad de conocer la lengua griega para entender los autores latinos y acceder al conocimiento de las fuentes en general. También Melanchthon se ocupa de la lengua hebrea a la que dedica la obra De lingua hebraicae (I546).

${ }_{25}$ Esta obra fue impresa, por primera vez, en Amberes (I488). 
No cabe duda de que la preocupación de Melanchthon por los aspectos didácticos y pedagógicos en la enseñanza, alimentaron el propio pensamiento de Lutero al respecto e hizo que en este campo la sintonía entre Melanchthon y Lutero fuera total. Tal hecho explica los resultados positivos obtenidos por la Reforma en materia de enseñanza en aquellas ciudades alemanas donde la nueva enseñanza se organizaba. Con el tiempo, la labor didáctica de Melanchthon ha sido reconocida, considerando su obra reformadora como un activo importante en la tradición de la pedagogía alemana (Egido, 2006: 27).

\subsection{Calvino y la Ratio studiorum protestante}

Independientemente de lo controvertida que es la figura de Calvino, tanto en lo personal como en lo doctrinario y, sobre todo, como hombre reformador, hay que reconocerle aspectos de su vida y de su obra que contribuyeron al desarrollo y consolidación de la reforma protestante iniciada por Lutero (Gomis, 1993: 208-209).

Calvino, por fecha de nacimiento (I509), por época cultural (vigencia del $\mathrm{Hu}$ manismo renacentista) y por formación (hombre de letras y leyes), respira el aire cultural de la Europa del siglo xvi, tiempo de modernización y de reformas. Pudo más en su vida y en su obra este clima de renovación cultural que sus rasgos de personalidad y su tendencia a interpretar determinadas cuestiones doctrinales $\mathrm{y}$, sobre todo, a cómo orientó la práctica de la organización de la reforma.

Por todo lo dicho anteriormente, Calvino puede ser calificado como hombre renacentista, aunque es posible decir de él que tuvo una particular visión del hombre y de la civilización (Léonard, 1967). Su visión del hombre le hace establecer, por una parte, una relación fundamental y sincera con Dios, lejos de fariseísmo e hipocresía, lo que explica, en buena medida, su rigor y también rigidez al enjuiciar los comportamientos no adecuados de los creyentes. Pero, por otra parte, Calvino considera que la acción del hombre debe ser útil, práctica y eficaz. Esta visión de la acción práctica se la aplica asimismo Calvino en toda su actividad, tanto doctrinal como organizativa, tal como puso de manifiesto en la orientación práctica de dos de sus trabajos importantes, la Institución de la religión cristiana, considerada como su obra principal, y las Ordenanzas eclesiásticas.

En cuanto a su visión de la civilización, del mundo, y coherente con la imagen que tenía del hombre (sentido práctico y útil), la acción de este en la sociedad se debe caracterizar, en opinión de Calvino, por su sentido ético en la vida del trabajo y en los negocios, lo que contribuyó, ciertamente, al desarrollo del capitalismo, tal como Max Weber lo analizó en su libro La ética protestante y el espíritu del capitalismo (Weber, 1977). No cabe duda de que la preocupación y la angustia que el hombre tenía por el más allá, por la cuestión de la predestinación, acentuaba en el creyente calvinista el buen hacer en el obrar, con lo que se colabora a la mayor gloria de Dios, en opinión de Calvino.

Hay otro aspecto relacionado también con la visión que Calvino tenía del mundo: la defensa fuerte que siempre hizo de la relativa autonomía que debe 
JUAN LUIS MONREAL PÉREZ

existir entre los poderes civiles y los eclesiásticos; planteamiento que se constituyó en un principio orientador de toda su política organizativa en la Iglesia de Ginebra (Wendel, 1985).

Esta forma de entender Calvino cómo estar y actuar en la sociedad le condujo a tener una visión de esta, en términos de cambio y de progreso, que exigía del creyente un compromiso y una coherencia entre su vida de fe y su obrar.

\subsection{Humanismo y Calvino}

No cabe duda de que la cultura dominante en Calvino es la humanista. Su tiempo y su formación le condicionaron, por encima de otros aspectos, a tener una mirada del hombre y de la sociedad con los valores propios del Humanismo renacentista europeo. Su condición de creyente, de hombre reformador y de organizador de la Iglesia ginebrina, en última instancia, no le apartó de la filosofía humanista, a pesar de que, en algunas cuestiones, esta se viera afectada por la rigidez de su personalidad y por algunos de sus planteamientos doctrinales.

\subsubsection{Calvino y la enseñanza}

La enseñanza fue uno de los campos que más ocupó a Calvino y constituye el núcleo de sus preocupaciones (Crouzet, 200I: 138). Esta la pensó y la organizó desde el espíritu del Humanismo, al considerar que la enseñanza es un motor fundamental para el progreso de la sociedad. Con este planteamiento Calvino se adhiere al movimiento reformista en materia de educación y enseñanza, impulsado por los reformadores que le habían precedido, como Lutero, Melanchthon, Zwinglio... Desde el momento de su llegada a Ginebra, Calvino se suma al movimiento proenseñanza que la ciudad de Ginebra, una vez adherida a la Reforma, había promovido con la creación del Establecimiento de instrucción pública bajo la iniciativa de Farel en I536 (Gomis, I993: I82). Coherente con esta visión, buena parte de la intensa actividad que Calvino desarrolla en su condición de líder de la Iglesia de Ginebra irá orientada a poner las bases normativas y organizativas de la enseñanza.

Una vez que Calvino se consolida en el liderazgo reformador de la ciudad, empieza a tomar las decisiones en materia de enseñanza que supondrían un claro avance respecto a los años anteriores. Resultado de las mismas fue la reorganización de la escuela que llevó a cabo, incorporando -además- en la misma los estudios superiores, con la finalidad de formar bien a la clase dirigente de la Iglesia de Ginebra, así como mostrar hacia fuera la excelencia del sistema de enseñanza que se impartía en la ciudad.

El proyecto de reforma de enseñanza que Calvino emprende está orientado por el espíritu humanista, impulsor de una pedagogía activa y de participación que favorece la implicación de los alumnos y el compromiso de los docentes, 
cuyo resultado manifiesto será la facilitación del aprendizaje (Crouzet, 20or: 138). Además del aprendizaje de las disciplinas establecidas por la organización escolar, que constituye uno de los objetivos del sistema de enseñanza de la Iglesia de la Reforma, Calvino tiene también muy presente en la programación educativa la dimensión religiosa de la enseñanza, es decir, que el tiempo y el espacio del aprendizaje sirviera también para iniciar y educar a los alumnos en los principios cristianos. A tal fin, el reformador preparó su propia versión del Catecismo (I54I) para asegurar que la enseñanza garantizara realmente la educación cristiana.

\subsubsection{Calvino y la organización de la enseñanza}

La visión y objetivos que Calvino asigna a la enseñanza necesitaban de unos instrumentos organizacionales y normativos que permitieran llevarse a cabo. A tal fin, desde el punto de vista de la organización de la enseñanza, Calvino se apoya en dos estructuras organizativas docentes. Por una parte, el Colegio o schola privata, continuación de la anterior escuela de latín, y en la que se enseñaba latín, griego y filosofía, orientado por la pedagogía humanista y marcado por la fe y el orden. Por otra parte, la Academia o schola publica, en la que se enseñaba teología filosofía, que comprendía física, matemática, dialéctica y retórica, y además de griego y hebreo; estaba organizada también según el modelo humanista y se tuvieron en cuenta las experiencias de enseñanza de Estrasburgo y Wittenberg en las correspondientes Academias de estas ciudades que Sturm y Melanchthon impulsaron (Gomis, 1993: 182-184 y Crouzet, 200I: 138-I40).

En la organización de estos dos niveles de enseñanza, Calvino -a pesar de la austeridad y rigidez que le acompañaban permanentemente- valoró la importancia de una disciplina soportable, el equilibrio entre carga docente y descanso, así como la conveniencia de invertir en la buena formación del profesorado y en las adecuadas condiciones materiales y de localización de los edificios donde se imparte la docencia. La aplicación de las medidas anteriores se tradujo en éxito y reconocimiento de la experiencia educativa, tanto en esta ciudad como en el exterior $^{26}$, y con el objetivo de darle continuidad en el tiempo, Calvino la protegió con las llamadas Leges Academiae Genevensis.

\subsubsection{Calvino y el uso de las lenguas en la enseñanza}

Fiel a la tradición humanista, Calvino incorpora en su organización de la enseñanza (Ratio studiorum) el aprendizaje y el uso de las lenguas clásicas, latín, griego y hebreo, asignando al latín el mayor peso entre ellas (Crouzet, 200I: I38-I39).

26 El número de alumnos de la institución docente creció de año en año a partir de los ciento sesenta y dos estudiantes iniciales, alcanzando un volumen notable de alumnos en 1564, año de la muerte de Calvino (Gomis, I993: 184). 
En cuanto al uso y al aprendizaje de las lenguas vernáculas, concretamente el francés, lengua materna de Calvino por su origen francés y lengua local de Ginebra, Calvino lo incluye en la programación docente con absoluta normalidad. Posiblemente influye en ello tanto su fecha de nacimiento (1509), más tardía que la de los otros humanistas examinados en el artículo, como su condición de reformador protestante, que le hacía ser más proclive al uso de las lenguas vernáculas. Como ejemplos del uso del francés, cabe mencionar: I.- Que la obra principal de Calvino, titulada la Institución de la religión cristiana, fue escrita en latín (I536), de la que hizo varias revisiones y ediciones en esta lengua. Pero Calvino quiso también difundirla en francés, haciendo igualmente varias versiones (Gomis, 1993: 80-8I); 2.- Que, en I543, Calvino para favorecer la plegaria participa en la edición de una compilación que contiene una cincuentena de salmos traducidos al francés (Crouzet, 200I: 137); 3.- Que la enseñanza en el colegio (Schola privata) se impartía en francés (Gomis, 1993: 184). Más concretamente, los correspondientes grados séptimo y sexto de dicha Escuela se dedicaban al aprendizaje de la escritura y de la lectura en latín y francés (Crouzet, 200r: 138).

El interés de Calvino por la enseñanza y el aprendizaje de las lenguas tuvo impacto en la ciudad y también en el exterior, como se ha señalado anteriormente, hasta tal punto que para otros humanistas del momento Calvino les sirvió de referente. Este es el caso de Johannes Funguerius [Juan Fungueiro], nacido en Frisia (Países Bajos, I546). Su lugar de nacimiento le llevó a vivir el humanismo propio del norte de Europa en el siglo xvi, y su lugar de formación, Lovaina y Colonia, le aproximó también a humanistas europeos tan reconocidos en aquel momento como Erasmo, Vives y Melanchthon (Comella, 20I8: 5). Ello explica que el conjunto de su obra tenga un marcado carácter humanista, siendo su primer escrito el Libro sobre la buena enseñanza y educación de jóvenes [De puerorun disciplina et recta educatione liber, 1584], un amplio tratado de Pedagogía y de clara orientación calvinista. Desde el punto de vista del aprendizaje de las lenguas, Fungueiro defiende la conveniencia de iniciarse en las mismas a edad temprana y siguiendo los modelos clásicos de aprendizaje.

\section{Conclusión}

El análisis realizado a lo largo del artículo nos conduce a concluir, por una parte, que todos los humanistas renacentistas europeos examinados en el texto (Erasmo, Vives, Ignacio de Loyola, Melanchthon y Calvino) participan de la cultura humanista, bien que haya que identificar en ellos grados diferentes de adhesión a la misma. Por otra parte, estos humanistas en sus Ratio studiorum incorporaron el aprendizaje de las lenguas clásicas, latín, griego y hebreo; asimismo, todos ellos consideraron la utilidad del uso de las lenguas vernáculas, aunque en grado diferente. La fecha de nacimiento, como la pertenencia al humanismo protestante o católico, pueden explicar en buena medida la mayor o menor apuesta por las lenguas vernáculas en el sistema de enseñanza (Ratio studiorum) que 
promovieron. La tradición de la corriente humanista protestante era más proclive al uso de las lenguas vernáculas que la católica.

\section{Bibliografía}

Albistur, F. X.: Ignacio de Loyola. Un líder para hoy, Bilbao, Ediciones Mensajero, 2017.

Batllori, M.: «En torno a los jesuitas, del Renacimiento a la Contrarreforma», Archivum Historicum Societatis Iesu, Roma, LIX, I990, pp. II7-I32.

Bayod, J. y Parellada, J.: «Estudio introductorio: Erasmo de Rotterdam, humanista y teólogo», en Erasmo de RotTerdam, Madrid, Gredos, 2oir, pp. xi-CV.

Bertran, M.: La Pedagogía de los jesuitas en la Ratio studiorum. La fundación de colegios. Orígenes, autores y evolución bistórica de la Ratio. Análisis de la educación religiosa, caracterológica e intelectual, Caracas, Ed. Arte, 1984.

Calero, F.: «La lengua vernácula y Luis Vives: a propósito de la autoría del Diálogo de la Lengua. Espéculo», Revista de Estudios Literarios, n. ${ }^{\circ}$ 4I (2009).

Chaparro, C.: «Introducción», en Erasmo De RotTerdam, D.: La Lengua, traducción y notas de La Lengua por Manuel Mañas Núñez y Luis Merino Jerez, Mérida, Editora Regional de Extremadura, 2007, pp. 15-43.

Codina, G.: Aux sources de la Pédagogie des jésuites. Le modus parisiensis, Roma, Institutum historicum S. I., 1968.

Comella, B.: «Estudio Preliminar», en Fungueiro, J.: Libro sobre la buena enseñanza y educación de los jóvenes (1584). [De puerorun disciplina et recta educatione liber], introducción y Estudio preliminar por Beatriz Comella y traducción y notas de Virgilio Rodríguez. Madrid, Universidad Nacional de Educación a Distancia y Biblioteca de Autores Cristianos (BAC), 20I8, pp. 5-324.

Crouzet, D.: Calvino, Barcelona, Editorial Ariel, $200 I$.

Egido, T. (ed.): Lutero, Obras, Salamanca, Ediciones Sígueme, 2006.

Eisner, E. W.: «Los objetivos educativos: ¿Ayuda o Estorbo?», en Gimeno Sacristán, J. y Pérez Gómez, A.: La enseñanza: su teoría y su práctica, Madrid, Akal, 1983, pp. 257-264.

ERASMO DE RotTERDAM: Obras escogidas, traslación castellana directa, comentarios, notas y un ensayo biobibliográfico por Lorenzo Riber, Madrid, Aguilar, 1964.

ERASMO DE ROTTERDAM: La paráclesis o exhortación al estudio de las letras divinas, edición y prólogo de Dámaso Alonso, reimpresión facsimilar, Madrid, Consejo Superior de Investigaciones Científicas (CSIC), I971.

ERASMO DE RotTerdam: Coloquios familiares, edición de Alonso Ruiz de Virués (siglo xvi), edición actualizada, estudio introductorio y notas de Andrea Herrán y Modesto Santos, Barcelona, Anthropos, 2005.

ERAsmo de RotTerdam: La Lengua, introducción de César Chaparro, traducción y notas de La Lengua por Manuel Mañas Núñez y Luis Merino Jerez, Mérida, Editora Regional de Extremadura, 2007.

Erasmo de Rotterdam: Adagios del poder y de la guerra y Teoría del Adagio, edición de Ramón Puig de la Bellacasa, Madrid, Alianza Editorial, 2008.

ERASMO De RotTerdam: Erasmo de Rotterdam, estudio introductorio por Jordi Bayod y Joaquín Parellada, Madrid, Gredos, 2011.

EsPino, J.: Evolución de la enseñanza gramatical jesuítica en el contexto socio-cultural español entre los siglos XVI y primera mitad del XVIII, Madrid, Universidad Complutense, 2005.

Esteban, L. (ed.): Cuatro estudios a una obra o el «Arte de Enseñar» de Juan Luis Vives, Valencia, Ayuntament de Valencia, 1997. 
Faubell, V.: «Melanchthon, Felipe (I497-1560)», en Escolano, A.: Historia de la Educación I, Madrid, Editorial Anaya, I984, pp. I2I-I22.

Fontán, A.: «El latín de Luis Vives», en SAinz Rodríguez, P. et al.: Homenaje a Luis Vives, Madrid, Fundación Universitaria Española, 1977, pp. 33-62.

Fontán, A.: Juan Luis Vives (I492-I540). Humanista. Filósofo. Político, Valencia, Ajuntament de València, 1992.

FungueIro, J.: Libro sobre la buena enseñanza y educación de los jóvenes (1584). [De puerorun disciplina et recta educatione liber], edición bilingüe preparada por Beatriz Comella y Virgilio Rodríguez, Madrid, Universidad Nacional de Educación a Distancia y Biblioteca de Autores Cristianos (BAC), 2018.

García, A. (ed.): Los dísticos de Catón comentados, edición, traducción y notas, Vigo, Universidade de Vigo, 1997.

GARcía, R.: «Ignacio de Loyola en perspectiva protestante», Gregorianum, 84, I (2003), pp. I03-I22.

Gomis, J.: Calvino, una vida por la Reforma, Barcelona, Editorial Planeta, 1993.

González-Blanco, E.: "Las traducciones romances de los Disticha Catonis», eHumanista, vol. 9, 2007, pp. 20-82.

Halkin, L-E.: Erasmo, México, Fondo de Cultura Económica, 197I.

Hofmann, F.: «Philipp Melanchthon und die zentralen Bildungsprobleme des Reformationsjahrhunderts», en Melanchthon, Ph.: Humanist, Reformator, Praeceptor Germaniae, Berlin, Akademie - Verlag, I963, pp. 83-I09.

KöBling, R.: «Philipp Melanchthon als Grammatiker der lateinischen Sprache», en WARTENBERG, G. et al:: Werk und Rezeption Philipp Melanchthon in Universität und Schule bis ins I8, Jahrhundert. Universität Leipzig, Evangelische Verlagsanstalt, I999.

LABRADOR, C.: «Felipe Melanchthon, iniciador de la segunda enseñanza humanística», Revista Miscelánea Comillas, n. ${ }^{\circ} 42$ (1984), pp. I7-36.

Labrador, C.: «Estudio histórico-pedagógico», en Gil Coria, E. (ed.): La pedagogía de los jesuitas, ayer y hoy, Madrid, Universidad Pontificia de Comillas, I999a, pp. $23-58$.

Labrador, C.: «La Ratio Studiorum de I599. Un sistema educativo singular», Revista de Educación, n. ${ }^{\circ} 319$ (1999b), pp. II7-I34.

LABRADOR, C.: «La Ratio Studiorum de 1599: un modo de ser y hacer en educación. Signos Universitarios», Revista de la Universidad del Salvador, año 32, n. ${ }^{\circ} 49$ (2013), pp. 69-93.

LÉonard, E. G.: Historia general del Protestantismo, vol. ı: La Reforma, Madrid, Península, 1967.

Maron, G.: Ignatius von Loyola. Mystik-Theologie-Kirche, Göttingen, Vandenhoeck \& Ruprecht, 200I.

Monreal, J. L.: «Juan Luis Vives, lengua y lenguaje en el humanismo renacentista», Revista Anales del Seminario de Historia de la Filosofía, vol. 28 (20II), pp. IOI-I33.

Monreal, J. L.: «La contribución de Philipp Melanchthon, Praeceptor Germaniae, a la lengua y a la enseñanza. Entre la cultura humanista europea y la reforma alemana», Historia de la Educación, vol. 36 (2017), pp. 207-228.

Moreno, V.: La recepción hispana de Luis Vives, Valencia, Conselleria de Cultura, Educaciò i Esport, 2006.

Nadal, J.: Jerónimo Nadal. Vida e influjo, Bilbao, Ed. Mensajero, 2007.

NúÑEz, J. M.: El ciceronianismo en España, Valladolid, Universidad de Valladolid, 1993.

Pardo Bazán, E.: Los Pedagogos del Renacimiento, Madrid, Fontanet, I899.

Pérez De ChInchón, B.: La lengua de Erasmo nuevamente romançada por muy elegante estilo, edición de Dorothy S. Severin, Madrid, Anejo xxxi del Boletín de la Real Academia Española, 1975.

Ponce DE LEÓN, R.: «Las propuestas metodológicas para la enseñanza del latín en las escuelas portuguesas de la Compañía de Jesús a mediados del siglo XvI», en Cuadernos de Filología Clásica, Estudios Latinos, 19 (2000), pp. 233-257. 
Rambla, J.: Ejercicios Espirituales de San Ignacio de Loyola. Una relectura del texto (I), Barcelona, Edicions Rondas, 2008.

Revuelta, M.: «Los colegios de la Compañía de Jesús. Tres momentos de su evolución histórica», Razón y Fe, IOI7 (1983).

Riber, L.: «Ensayo bio-bibliográfico: Juan Luis Vives, valenciano», en Vives J. L.: Obras Completas, tomo I, Madrid, Editorial Aguilar, 1947.

Richard, J. W.: Philip Melanchthon, the Protestant preceptor of Germany, I497-I560, New York/London, (ed.) G.P. Putnams' sons, 1902.

Rupp, H. F.: «Philipp Melanchthon (I497-I560)», Revista Perspectivas, vol. xxvi, n. ${ }^{\circ}$ 3, septiembre (1996), pp. 659-669.

Scheible, H.: Melanchthon-Eine Biographie, München, Editorial C.H. Beck, 1997.

STroh, W.: El latín ha muerto. ; Viva el latin!, Barcelona, Ediciones del Subsuelo, 2012.

Stupperich, R.: Melanchthon, Berlin, Gruyter, I960.

Tröhler, D.: Los lenguajes de la educación, Barcelona, Editorial Octaedro, 2013.

Vergara, J.: «El humanismo pedagógico en los colegios jesuíticos del siglo XVI», Revista Studia Philologica Valentina, vol. Io, n. ${ }^{\circ} 7$ (2007), pp. I7I-200.

Villalpando, J. M.: «Estudio preliminar y prólogos», en Vives, J. L.: Tratado de la Enseñanza, Introducción a la sabiduría, Escolta del alma, Diálogos, Pedagogía Pueril, México, Editorial Porrúa, 1984, pp. 299-300; 313-314.

Vives, J. L.: Obras Completas por Lorenzo Riber (traslación, comentarios, notas y ensayo bibliográfico), tomo II, Madrid, Editorial Aguilar, 1948.

Vives, J. L.: Tratado de la Enseñanza, Introducción a la sabiduría, Escolta del alma, Diálogos, Pedagogía Pueril, México, Editorial Porrúa, 1984.

Weber, M.: La ética protestante y el espíritu del capitalismo, Barcelona, Editorial Península, 1977.

WeNDEL, F: Calvin. Sources et évolution de sa pensée religieuse, Genève, Labor et Fides, I985.

Woodward, W. H.: Studies in Education during the Age of Renaissance. 1400-I600, New York, Teachers College Press, Columbia University, 1967. 